\title{
TRICHOMONIASIS: CONVENTIONAL DIAGNOSTIC TECHNIQUES IN SYMPTOMATIC AND ASYMPTOMATIC WOMEN.
}

\author{
$\mathscr{B y}$ \\ Wafaa A. Abou-kamara, Raefa A. Atia ${ }^{a}$, Hala A. El-nahasa, \\ Aida A. Abd el-mageida, Mohammed A. Mosbah ${ }^{b}$, \\ Nora L. El-Tantawya. \\ Trom \\ a: Department of Parasitology, Faculty of Medicine, Mansoura \\ University, Mansoura 35516, Egypt \\ b: Department of Obstetrics and Gynecology, Faculty \\ of Medicine, Mansoura University, Mansoura 35516, Egypt
}

\begin{abstract}
Objectives: To estimate Trichomonas vaginalis prevalence in symptomatic and asymptomatic cases using wet amount preparation and modified Diamond's culture.

Materials and Methods: Two hundred females were enrolled in this study, 100 were symptomatic while other 100 were asymptomatic. Vaginal swabs samples were collected and examined using both wet mount and modified Diamond's culture methods.
\end{abstract}

Results: The allover prevalence of trichomoniasis was $13.5 \%$ in the studied cases. By wet mount, $12 \%$ (12/100) were positive for T. vaginalis in symptomatic group while, only $1 \%(1 / 100)$ were positive in asymptomatic group, whilst using modified Diamond's culture, 22 cases $(22 \%)$ in symptomatic and 5 cases $(5 \%)$ in asymptomatic groups.

Conclusions: In our locality, modified Diamond's culture is more sensitive in diagnosis of trichomoniasis than wet amount preparation by microscopy.

Keywords: Trichomonas vaginalis- Prevalence- Wet amount- Culture- Symptomatic - Asymptomatic.

MANSOURA MEDICAL JOURNAL 
240 TRICHOMONIASIS: CONVENTIONAL DIAGNOSTIC etc...

\section{INTRODUCTION}

Trichomoniasis is caused by Trichomonas vaginalis ( $T$. vaginalis). Trichomoniasis is the commonest non-viral sexually transmitted diseases (STDs) world-wide [1]. Trichomoniasis global prevalence has a wide scale and was estimated $8.1 \%$ in female and $1.0 \%$ in male [2]. Prevalence is underestimated due to the low sensitivity of diagnostic tests; particularly many studies depend on wet mount technique rather than the more sensitive nucleic acid amplification test (NAAT). So, difference in prevalence of $T$. vaginalis is due to variation in population and geography [3]. Mainly, T. vaginalis colonizes on the squamous epithelium of the genital tract. T. vaginalis. The incubation period has wide range from 4 to 28 days [4, 5]. Common signs and symptoms of acute infection include: vaginitis; a purulent, malodorous, thin discharge associated with burning, pruritus, dysuria, frequency of micturition, lower abdominal pain, dyspareunia or strawberry cervix [6, 7]. Other complications like inflammatory pelvic disease, premature rupture of membranes, abortion, low birth weight, and increased infant mortality [8]. More seriously, individu- als suffering from trichomoniasis are at more risk to gain human immunodeficiency virus infection in comparison to the general population [9].

The most common diagnostic method for detection of $\mathrm{T}$. vaginalis infection in women is wet mount preparation from vaginal secretions examined by microscopic examination. Direct detection of the pearshaped motile $T$. vaginalis with jerky is considered $100 \%$ specific for trichomoniasis but this method has poor sensitivity [10, 11]. The gold standard test for diagnosis of $\mathrm{T}$. vaginalis is the culture [12]. Diamond's medium Culture of $\mathrm{T}$. vaginalis has more sensitivity over direct wet mount microscopic examination [10]. Immediately, samples from vaginal swabs should inoculate in the culture medium as soon as possible [13, 14]. Asymptomatic trichomoniasis varies from $25 \%$ up to $50 \%$ and Comprehensive guidelines for diagnosis of trichomoniasis are lacking $[15,16]$.

In our locality, T. vaginalis diagnosis is usually based on presence of clinical manifestation of trichomoniasis. However, many asymptomatic cases can be lost without proper 
management. So, considering the necessity of identification and treatment of trichomoniasis in both symptomatic and asymptomatic individuals, this study aimed to determine the prevalence of trichomoniasis in our locality using both wet mount and culture techniques.

\section{SUBJECTS AND METHODS}

The present comparative study was done in medical Parasitology laboratory, Parasitology department, Mansoura University. All cases were chosen from Obstetrics and Gynecology out-patients clinic, Mansoura University Hospitals in period from June 2014 to July 2015. A consent were obtained from all participants.

\section{Subjects:}

Two hundred females were enrolled in this study, 100 were symptomatic while other 100 were asymptomatic. All patients were subjected to the following:

1. Full medical history regarding age, locality, marital status and symptoms suggesting trichomoniasis (vaginal discharge, dysuria, dyspareunia, itching, and partner symptoms
2. Clinical examination: local examination, including inspection (for sign of inflammation and discharge), examination of external genitalia, and speculum examination (for cervical and vaginal discharge).

\section{METHODS}

Sample Collection:

Three vaginal specimens were collected using sterile cotton swab from the posterior fornix through speculum examination, one swab was put in $2 \mathrm{ml}$ Phosphate buffer saline solution (PBs) for wet mount microscopic examination and the others for culture method.

Microscopy examination:

A- Wet amount preparation: Swab was mixed in 1-2 ml of PBs solution $(8 \mathrm{~g} \mathrm{NaCl}, 0.2 \mathrm{~g} \mathrm{KCl}, 1.44 \mathrm{~g}$ $\mathrm{Na} 2 \mathrm{HPO} 4$ and $0.24 \mathrm{~g} \mathrm{KH} 2 \mathrm{PO} 4$ were supplied from El Nasr Pharm Chemical Co., Abu Zaabal, Egypt). One to two drops were put on dry slide then the cover was applied then the slide was examined microscopically under dark ground illumination at x200, x400 and x1000 magnifications for evidence of motile $T$. vaginalis within 0.5-1 hours after MANSOURA MEDICAL JOURNAL 


\section{TRICHOMONIASIS: CONVENTIONAL DIAGNOSTIC etc...}

sampling time [17].

B- Modified Diamond's medium: Culture media was prepared according to (Diamond et al. [18], supplemented with streptomycin - penicillin at $50 \mu \mathrm{g} / \mathrm{mL}$ and $10 \%$ heat-inactivated horse serum and incubated at $37^{\circ} \mathrm{C}$. Firstly, tubes with $10 \mathrm{ml}$ of liquid media were incubated at $37{ }^{\circ} \mathrm{C}$ for 10 to 15 minute before use. The other two vaginal swabs were put then cultures were incubated for 5-7 days and examined for the presence of $T$. vaginalis by microscopy each day for five to seven days post-inoculation. Under sterile condition, few drops by disposable sterile pasteur pipettes were taken from culture for detection of motile $T$. vaginalis as the same method of wet mount method [18, 19].

\section{Approval:}

Approval to carry this study was obtained from both the Ethics Review Committees and the institutional review boards of the faculty of medicine, Mansoura University, Egypt.

Inclusion criteria:

One hundred female patients aged from 18 to 58 years presented with symptoms suggesting tichomoniasis (vaginal discharge, dysuria, dyspareunia, itching, and partner symptoms, and asymptomatic one hundred female attended for infertility management, to receive contraceptive method who served as a comparative group.

\section{Exclusion criteria:}

Those who are pregnant, received antiparasitic, antitrichomonal therapy, under hormonal therapy, or used vaginal wash within the previous two weeks were excluded from the study.

\section{Statistical analysis:}

Data were fed to the computer and analyzed using IBM SPSS software package version 20.0. Qualitative data were described using number and percent. Quantitative data were described median, minimum maximum. The results was considered Significant when the probability of error is less than $5 \%(p<0.05)$.

\section{RESULTS}

The relevant characteristic of 200 females enrolled in this study in both groups is displayed in table (1) with the Sociodemographic characters in 
symptomatic group and asymptomatic cases including age, marital status and residence. All the study participants were stratified into 4 group according to their age, the median age of symptomatic cases was 32.0 (18.0-58.0) years and 36.0 (19.058.0) years in asymptomatic cases, with statistical significant difference between two groups $(P=0.05)$. The age group 28- years was highest in both symptomatic and asymptomatic groups with statistical significant difference $(P=0.05)$. There was significant difference as regarding age, while no significant variation of marital status and residence between symptomatic or asymptomatic studied cases $(P>0.05)$.

Table (2) shows the self-reported symptoms of symptomatic positive $T$. vaginalis patients. Vaginal discharge was detected in $80(81.8 \%)$ cases, lower abdominal pain and itching in fourteen cases (63.6\%), dyspareunia in eleven cases $(50 \%)$ and itching was presented in 9 (40.9\%) cases.

Using wet amount preparation technique, $T$. vaginalis was detected in 12 cases out of 100 symptomatic cases $(12 \%)$ and one case out of
100 asymptomatic cases (1\%) table (3) with high statistical significant different in detection of $\mathrm{T}$. vaginalis in symptomatic cases $(p<0.05)$.

Table (4) shows the detection of $\mathrm{T}$. vaginalis in symptomatic and asymptomatic groups using modified Diamond's culture. In symptomatic group, 22 cases were detected (22\%), while in asymptomatic cases, five cases were found (5\%). There was highly statistically significant difference in detection of $T$. vaginalis in symptomatic positive cases in comparison of detection in asymptomatic positive cases $\left(p=0.001^{*}\right)$.

Table (5) shows the descriptive statistical analysis of microscopic examination of $T$. vaginalis detection in symptomatic and asymptomatic cases in comparison to golden standard modified Diamond's culture. Using modified Diamond's culture, twenty seven positive cases of $T$. vaginalis were detected out of 200 symptomatic and asymptomatic cases and 173 cases were negative. Using wet amount microscopic examination 13 positive $T$. vaginalis cases were found and 187 cases were negative: Nine cases were positive by both wet amount and modified Diamond's

MANSOURA MEDICAL JOURNAL 
244 TRICHOMONIASIS: CONVENTIONAL DIAGNOSTIC etc...

culture and 4 cases were positive by with wet amount microscopic examiwet amount only and were consid- nation. Wet amount microscopic exered as false positive result. There amination has sensitivity of (33.3), was highly statistical significant dif- specificity of (97.7), positive predicference $\left(p<0.001^{*}\right)$ using modified tive value of (69.2) and negative preDiamond's culture in comparison dictive value of (90.4). 
Table (1): Sociodemographics of the study participants.

\begin{tabular}{|c|c|c|c|}
\hline & $\begin{array}{c}\text { Symptomatic } \\
\text { cases } \\
n=100 \mathrm{n}(\%)\end{array}$ & $\begin{array}{c}\text { Asymptomatic } \\
\text { cases } \\
\mathbf{n}=100 \mathrm{n}(\%)\end{array}$ & $\begin{array}{c}\text { Test of } \\
\text { significance } \\
P \text { value }\end{array}$ \\
\hline \multicolumn{4}{|l|}{ Age } \\
\hline $\begin{array}{c}\text { Median } \\
(\text { min-max })\end{array}$ & $\begin{array}{c}32.0 \\
(18.0-58.0)\end{array}$ & $\begin{array}{c}36.0 \\
(19.0-58.0)\end{array}$ & $\begin{array}{l}\mathrm{Z}=3.14 \\
P=0.002 *\end{array}$ \\
\hline \multicolumn{4}{|l|}{ Age groups } \\
\hline $18-$ & $23(23.0)$ & $7(7.0)$ & \multirow[t]{4}{*}{$\begin{array}{l}\mathrm{MC} \\
P=0.004^{*}\end{array}$} \\
\hline 28- & $45(45.0)$ & $45(45.0)$ & \\
\hline 38- & $23(23.0)$ & $27(27.0)$ & \\
\hline $48-58$ & $9(9.0)$ & $21(21.0)$ & \\
\hline Marital status & $\mathrm{n}(\%)$ & $\mathrm{n}(\%)$ & \\
\hline Married & $99(99.0)$ & $100(100.0)$ & \multirow[t]{2}{*}{$\begin{array}{l}\text { FET } \\
P=1.0\end{array}$} \\
\hline Divorced & $1(1.0)$ & $0(0.0)$ & \\
\hline \multicolumn{4}{|l|}{ Residence } \\
\hline Urban & $40(40.0)$ & $44(44.0)$ & \multirow[t]{2}{*}{$\begin{aligned}{ }^{2} & =0.328 \\
P & =0.67\end{aligned}$} \\
\hline Rural & $60(60.0)$ & $56(56.0)$ & \\
\hline
\end{tabular}

$Z=$ Mann Whitney test, FET: Fischer exact test, $\chi^{2}=$ Chis-quare test MC: Monte Carlo test, $* p$ valu/7e significant $<0.05$, $\mathrm{SD}=$ standard deviation

Table (2): Frequency of symptoms of symptomatic group.

\begin{tabular}{lll}
\hline & $\mathbf{n}=\mathbf{2 2}$ & $\mathbf{\%}$ \\
\hline Discharge & 18 & 81.8 \\
\hline Pain & 14 & 63.6 \\
\hline Dysparnia & 11 & 50.0 \\
\hline Dysuria & 9 & 40.9 \\
\hline Itching & 14 & 63.6 \\
\hline
\end{tabular}


Table (3): Microscopic examination for detection of vaginal trichomoniasis.

\begin{tabular}{cccc}
\hline Microscopy & $\begin{array}{c}\text { Symptomatic } \\
\text { group } \\
\mathrm{n}=\mathbf{1 0 0} \mathbf{n}(\%)\end{array}$ & $\begin{array}{c}\text { Asymptomatic } \\
\text { group } \\
\mathrm{n}=\mathbf{1 0 0} \mathbf{n}(\%)\end{array}$ & $\begin{array}{c}\text { Test of } \\
\text { significance }\end{array}$ \\
\hline T. vaginalis & $\left(\begin{array}{c}12(12.0) \\
\end{array}\right.$ & $1(1.0)$ & ${ }^{2}=9.96$ \\
& & & $\mathrm{p}=0.002^{*}$
\end{tabular}

Table (4): Modified Diamond's culture for detection of vaginal trichomoniasis.

\begin{tabular}{lccc}
\hline Culture & $\begin{array}{c}\text { Symptomatic } \\
\text { group }\end{array}$ & $\begin{array}{c}\text { Asymptomatic } \\
\text { group }\end{array}$ & $\begin{array}{c}\text { Test of } \\
\text { significance }\end{array}$ \\
& $\mathrm{n}=100$ & $\begin{array}{c}\mathrm{n}=100 \\
\mathrm{n}(\%)\end{array}$ & \\
\hline negative & $78(78.0)$ & $95(95.0)$ & \\
\cline { 1 - 2 } & & & $\begin{array}{r}{ }^{2}=12.37 \\
\mathrm{p}<0.001^{*}\end{array}$ \\
\hline
\end{tabular}

Table (5): Reliability of wet mount preparation in diagnosing all studied symptomatic and asymptomatic cases.

\begin{tabular}{|c|c|c|c|c|c|c|}
\hline \multirow{2}{*}{$\begin{array}{l}\text { Wet mount } \\
\text { preparation }\end{array}$} & \multicolumn{2}{|c|}{ Culture } & \multirow{2}{*}{$\begin{array}{c}\text { Test of } \\
\text { significance }\end{array}$} & \multirow{2}{*}{ 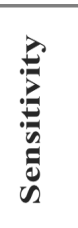 } & \multirow{2}{*}{ 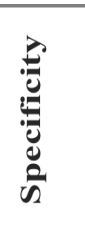 } & \multirow{2}{*}{ 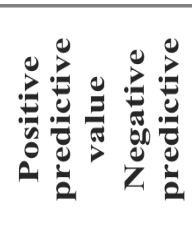 } \\
\hline & $\begin{array}{c}\text { negative } \\
\mathrm{n}=173 \\
\mathrm{n}(\%)\end{array}$ & $\begin{array}{c}\text { positive } \\
\mathrm{n}=27 \\
\mathrm{n}(\%)\end{array}$ & & & & \\
\hline negative & $\begin{array}{c}169 \\
(97.7)\end{array}$ & $18(66.7)$ & $\begin{array}{r}{ }^{2}=36.9 \\
\mathrm{P}<0.001^{*}\end{array}$ & 33.3 & 97.7 & 69.2 \\
\hline positive & $4(2.3)$ & $9(33.3)$ & & & & \\
\hline
\end{tabular}

Vol. 43, No. 1 \& 2 Jan. \& April, 2014 
Wafaa A. Abou-kamar et al ...

\section{DISCUSSION}

Trichomoniasis clinical manifestations are identical to those caused by other STDs and bacterial vaginosis. Common signs and symptoms of acute infection include: Vaginitis; a purulent, malodorous, thin discharge associated with burning, pruritus, dysuria, frequency, lower abdominal pain, or dyspareunia. Symptoms may be worse during menstruation [20]. Out of 200 female cases, we found $27 \mathrm{~T}$. vaginalis positive cases; Infection was more frequent in symptomatic $(22 / 100,22 \%)$ than in asymptomatic female $(5 / 100,5 \%)$, with agreement of Schwebke et al. [21] who detected trichomoniasis in symptomatic cases from $15 \%$ to $16.4 \%$ and in asymptomatic subject from $6.5 \%$ to $7.0 \%$ ) also, $\mathrm{Nu}$ et al. [22] demonstrated that trichomoniasis in $76 / 243(31.3 \%)$ cases were symptomatic and $71 / 534$ (13.3\%) cases were asymptomatic.

As regarding the symptomatic positive cases, their age ranged from 20.0 58.0 years with mean 35.09 years $\pm 9.82 \mathrm{SD}$ and in asymptomatic positive cases, their age ranged from 19-50 years with mean 33.2 years \pm 11.08 SD with agreement of Dharma et al. [23] (34 years old). The age of the studied subjects were in the reproductive age that has association with the active sexual behavior and may be due to deficient awareness about STIs [24], with agreement of Goo et al. [25] who documented that the median age of infected subjects in Daegu was 31.9 years old, Hussein et al. [26] reported that the age ranged from 20 to 50 years and the age varied from 20 to 60 years, mean $38+/-10$ in study done by $\mathrm{Nu}$ et al. [22]. As regarded age, we revealed significant correlation similar to that study done by Krashin et al. [27]

In the present study, $99 \%$ of symptomatic cases and $100 \%$ asymptomatic cases were married. Maina et al. [28] reported that $85 \%$ of cases were married, and Fernando et al. [29] found that $68 \%$ were married. There was no significant difference between symptomatic or asymptomatic positive cases $(P>0.05)$ as regard the marital status with agreement of the results reported by Fernando et al. [29].

Regarding the residence in our study, about $(60 \%)$ of the cases

MANSOURA MEDICAL JOURNAL 
248 TRICHOMONIASIS: CONVENTIONAL DIAGNOSTIC etc...

came from rural area and (40\%) of cases from urban area. Symptomatic and asymptomatic cases from rural area were more than those who came from urban area, There was no significant difference regarding residence $(P>0.05)$. Such finding coincides with that obtained by Silva et al. [30] \& Mahmoud et al. [31]. Conversely, Dahab et al. [32] reported statistical significant difference regarding areas of residence $(P<$ 0.05).

In our study, in symptomatic positive $T$. vaginalis cases. Vaginal discharge was detected in eighteen cases $(81.8 \%)$ with agreement of Schwebke et al. [21] who found that vaginal discharge was $(75.1 \%)$, and by Dharma et al. [23] it was (71.3\%), however Kaul et al. [33] found that $57.3 \%$ were having vaginal discharge, lower abdominal pain while, itching was found in fourteen cases (63.6\%), dyspareunia was reported in eleven cases $(50 \%)$ and dysuria was revealed in nine cases $(40.9 \%)$. Fernando et al. [29] detected dysuria in about $12 \%$ of cases.

Using wet amount method, T. vaginalis was detected in 12 cases out of 100 symptomatic cases (12\%) and one case out of 100 asymptomatic cases (1\%) with high statistical significant with agreement of Hegazy et al. [34] reported that $32.9 \%$ of symptomatic cases were positive and $13 \%$ of asymptomatic cases were positive. Nassef et al. [35] reported $30.2 \%$ in the symptomatic group and $22.7 \%$ positivity in the asymptomatic group. Dharma et al. [23] detected $13(1.7 \%)$ of symptomatic cases with the wet mount technique and reported 4 asymptomatic cases with trichomoniasis. Muzny et al. [36] documented that 736 of 3765 $(19.6 \%)$ were infected in symptomatic and asymptomatic cases and were less than those who detected by NAAT. In our study, Wet amount microscopic examination has sensitivity of (33.3), specificity of (97.7), positive predictive value of (69.2) and negative predictive value of (90.4) with agreement of Smith et al. [37] established that sensitivity of wet amount was $47.8 \%$ (27.4-68.9), specificity was $91.7 \%$ (79.1-97.3), positive predictive value was $73.3 \%$ (44.8-91.1) and negative predictive value was $78.6 \%$ (65.2-88.0). While sensitivity of wet amount in study done by Nassef et al. [35] was $80 \%$, 
specificity of $100 \%$ and positive predictive value of $100 \%$, negative predictive value of $90.2 \%$.

In our study, using modified Diamond's culture, 22 cases were detected $(22 \%)$ in symptomatic group, while in asymptomatic cases, five cases $(5 \%)$ were found. There was highly statistically significant difference in detection of $T$. vaginalis in symptomatic positive cases in comparison of detection in asymptomatic positive cases with agreement of study done by Nassef et al. [35] demonstrated $38.1 \%$ of symptomatic cases and $27.3 \%$ of asymptomatic cases. Shehabi et al. [38] detected $1.6 \%$ positively in symptomatic group and $0.5 \%$ positively in asymptomatic group. Hegazy et al. [39] reported that $43.7 \%$ of symptomatic cases were positive and $24.6 \%$ of asymptomatic cases were positive. Kaul et al. [33] documented that 37 symptomatic and asymptomatic cases were positive out of 463. Dharma et al. [23] reported that $T$. vaginalis infection was occurred in 16 cases $(2.1 \%)$ of studied participants. Fernando et al. [29] revealed that $\mathrm{T}$. vaginalis infection prevalence was $7.2 \%$ (25/ 346). On the other hand, many stud- ies found increased significant in asymptomatic cases in comparison with symptomatic group, Valadkhani et al. [40] detected $1.1 \%$ of asymptomatic group proved to have trichomoniasis and $0.8 \%$ of symptomatic group. Smith et al. [37] reported that culture technique was with sensitivity of $63 \%$ (42.5-79.9), specificity $100 \%$ (95.0-100), positive predictive value of $100 \%(77.1-100)$ and negative predictive value of $83.5 \%$ (82.1-94.9).

The wet mount microscopy is conventional method for trichomoniasis diagnosis [41] with many advantage including rapid, simple and low cost [42]. There are some limitations represented in examination which should be done within 30 minute of collection according to jerky movements of the trophozoite, the similarity between neutrophils and T.vaginalis, the need for expert physician and low sensitivity [31]. Radonjic et al. [43] and Hussein et al. [26] established that culture technique continue as the gold standard for trichomoniasis diagnosis. However, the molecular testing has established to have a higher sensitivity [12]. Culture of $T$. vaginalis has more MANSOURA MEDICAL JOURNAL 
TRICHOMONIASIS: CONVENTIONAL DIAGNOSTIC etc...

sensitivity over direct wet mount microscopic examination [10] and can demonstrate trichomonads in men [13]. The culture media are relatively inexpensive, however, require incubator, the culture must be examined daily and this increase the requirement for examination by a trained microscopist, and results may take up to a week with a late diagnosis of trichomoniasis [14, 31].

\section{CONCLUSION}

The prevalence of trichomoniasis was higher in symptomatic group than asymptomatic one. The culture was more sensitive than wet mount. In resource-poor settings, wet mount is a good option for diagnosing trichomoniasis but wherever facilities are available culture should be performed to identify wet mount negative cases.

\section{REFERENCES}

1. Conrad, M. D., Gorman, A. W., Schillinger, J. A., Fiori, P. L., Arroyo, R., Malla, N., \& Carlton, J. M. (2012) : Extensive genetic diversity, unique population structure and evidence of genetic exchange in the sexually transmitted parasite Trichomonas vaginalis. PLoS Negl Trop Dis, 6(3), e1573.

2. Johnston, V. J., \& Mabey, D. C. (2008) : Global epidemiology and control of Trichomonas vaginalis. Current opinion in infectious diseases, 21(1), 56-64.

3. Kissinger, P. (2015) : Trichomonas vaginalis: a review of epidemiologic, clinical and treatment issues. BMC infectious diseases, 15(1), 307.

4. Petrin, D., Delgaty, K., Bhatt, R., \& Garber, G. (1998) : Clinical and microbiological aspects of Trichomonas vaginalis. Clinical microbiology reviews, 11(2), 300317.

5. Coleman, J. S., Gaydos, C. A., \& Witter, F. (2013) : Trichomonas vaginalis vaginitis in obstetrics and gynecology practice: new concepts and controversies. Obstetrical \& gynecological survey, 68(1), 43. 
6. Heine, P., \& McGREGOR, J. A. (1993) : Trichomonas vaginalis: a reemerging pathogen. Clinical obstetrics and gynecology, 36(1), 137-144.

7. Byun, J. M., Jeong, D. H., Kim, Y. N., Lee, K. B., Sung, M. S., \& Kim, K. T. (2015) : Experience of successful treatment of patients with metronidazole-resistant Trichomonas vaginalis with zinc sulfate: A case series. Taiwanese Journal of Obstetrics and Gynecology, 54(5), 617-620.

8. Cherpes, T. L., Wiesenfeld, H. C., Melan, M. A., Kant, J. A., Cosentino, L. A., Meyn, L. A., \& Hillier, S. L. (2006) : The associations between pelvic inflammatory disease, Trichomonas vaginalis infection, and positive herpes simplex virus type 2 serology. Sexually transmitted diseases, 33(12), 747-752.

9. Kissinger, P., Amedee, A.,
Clark, R. A., Dumestre, J., Theall, K. P., Myers, L., \& Martin, D. H. (2009) : Trichomonas vaginalis treatment reduces vaginal HIV-1 shedding. Sexually transmitted diseases, 36 (1), 11.

10. Huppert, J. S., Mortensen, J. E., Reed, J. L., Kahn, J. A., Rich, K. D., Miller, W. C., \& Hobbs, M. M. (2007) : Rapid antigen testing compares favorably with transcription-mediated amplification assay for the detection of Trichomonas vaginalis in young women. Clinical Infectious Diseases, 45(2), 194-198.

11. Patil, M. J., Nagamoti, J. M., \& Metgud, S. C. (2012) : Diagnosis of Trichomonas vaginalis from vaginal specimens by wet mount microscopy, in pouch TV culture system, and PCR. Journal of global infectious diseases, 4(1), 22.

12. Sherrard, J., Ison, C., Moody, J., Wainwright, E., WilMANSOURA MEDICAL JOURNAL 
TRICHOMONIASIS: CONVENTIONAL DIAGNOSTIC etc...

son, J., \& Sullivan, A.

(2014) : United Kingdom national guideline on the management of Trichomonas vaginalis 2014. International journal of STD \& AIDS, 0956462414525947.

13. Nye, M. B., Schwebke, J. R., \& Body, B. A. (2009) : Comparison of APTIMA Trichomonas vaginalis transcription-mediated amplification to wet mount microscopy, culture, and polymerase chain reaction for diagnosis of trichomoniasis in men and women. American journal of obstetrics and gynecology, 200 (2), 188-e1.

14. Hobbs, M. M., Lapple, D. M., Lawing, L. F., Schwebke, J. R., Cohen, M. S., Swygard, H., \& Seña, A. C. (2006) : Methods for detection of Trichomonas vaginalis in the male partners of infected women: implications for control of trichomoniasis. Journal of clinical microbiology,
44(11), 3994-3999.

15. Piperaki, E. T., Theodora, M., Mendris, M., Barbitsa, L., Pitiriga, V., Antsaklis, A., \& Tsakris, A. (2010) : Prevalence of Trichomonas vaginalis infection in women attending a major gynaecological hospital in Greece: a cross-sectional study. Journal of clinical pathology, 63(3), 249-253.

16. Hobbs, M. M., \& Seña, A. C. (2013) : Modern diagnosis of Trichomonas vaginalis infection. Sexually transmitted infections, 89(6), 434438.

17. McCANN, J. S. (1974) : Comparison of direct microscopy and culture in the diagnosis of trichomoniasis. British Journal of venereal diseases, 50(6), 450.

18. Clark, C. G., \& Diamond, L. S. (2002) : Methods for cultivation of luminal parasitic protists of clinical importance. Clinical microbiology reviews, 15(3), 329-341. 
19. Diamond, L. S.; Clark, C. G.; Cunnick, C. C. (1995) : YI$\mathrm{S}$, a Casein-free Medium for Axenic Cultivation of Entamoeba histolytica, Related Entamoeba, Giardia intestinalis and Trichomonas vaginalis. Journal of Eukaryotic Microbiology, 42(3), 277-278.

20. Sena, A. C., Miller, W. C., Hobbs, M. M., Schwebke, J. R., Leone, P. A., Swygard, H., \& Cohen, M. S. (2007) : Trichomonas vaginalis infection in male sexual partners: implications for diagnosis, treatment, and prevention. Clinical Infectious Diseases, 1322.

21. Schwebke, J. R., Hobbs, M. M., Taylor, S. N., Sena, A. C., Catania, M. G., Weinbaum, B. S., \& Gaydos, C. A. (2011) : Molecular testing for Trichomonas vaginalis in women: results from a prospective US clinical trial. Journal of clinical microbiology, 49(12), 41064111.
22. Nu, P. A. T., Nguyen, V. Q. H., Cao, N. T., Dessì, D., Rappelli, P., \& Fiori, P. L. (2015) : Prevalence of Trichomonas vaginalis infection in symptomatic and asymptomatic women in Central Vietnam. The Journal of Infection in Developing Countries, 9(06), 655660.

23. Dharma MN, Umashankar KM, Sudha, Abed GN, Kavitha G. (2013) : Prevalence of the Trichomonas vaginalis infection in a tertiary care hospital in rural Bangalore, Southern India. Journal of Clinical and Diagnostic Research, 7(7), 1401-1403.

24. Ambrozio, C. L., Nagel, A. S., Jeske, S., Bragança, G. C. M., Borsuk, S., \& Villela, M. M. (2016) : Trichomonas vaginalis prevalence and risk factors for women in southern Brazil. Revista do Instituto de Medicina Tropical de São Paulo, 58, 61.

MANSOURA MEDICAL JOURNAL 
254 TRICHOMONIASIS: CONVENTIONAL DIAGNOSTIC etc...

25. Goo YK, Shin WS, Yang HW, Joo SY, Song SM, Ryu JS, Lee WM, Kong $\mathrm{HH}$, Lee WK, Lee SE, Lee WJ, Chung DI, Hong Y. (2016) : Preva-lence of Trichomonas vaginalis in women visiting 2 obstetrics and gynecology clinics in Daegu, South Korea. Korean J Parasitol, 54, 75-80.

26. Hussein, A. H., Saleh, M. H., Nagaty, I. M., Ghieth, K. A., \& El-Azab, N. A. (2015) : Prevalence, Clinical Criteria and Sociodemographic Predictors of Trichomonas vaginalis Infection in Suspected Egyptian Women, Using Direct Diagnostic Techniques. Iranian journal of parasitology, 10(3), 432.

27. Krashin, J. W., Koumans, E. H., Bradshaw-Sydnor, A. C., Braxton, J. R., Secor, W. E., Sawyer, M. K., \& Markowitz, L. E. (2010) : Trichomonas vaginalis prevalence, incidence, risk factors and antibioticresistance in an adolescent population. Sexually transmitted diseases, 37(7), 440-444.

28. Maina, A. N., Kimani, J., \& Anzala, O. (2016) : Prevalence and risk factors of three curable sexually transmitted infections among women in Nairobi, Kenya. BMC research notes, 9(1), 193.

29. Fernando, S. D., Herath, S., Rodrigo, C., \& Rajapakse, L. (2012) : Clinical features and sociodemographic factors affecting Trichomonas vaginalis infection in women attending a central sexually transmitted diseases clinic in Sri Lanka. Indian Journal of Sexually Transmitted Diseases and AIDS, 33(1), 25.

30. Silva, L. C. F., Miranda, A. E., Batalha, R. S., Monte, R. L., \& Talhari, S. (2013) : Trichomonas vaginalis and associated factors among women living with HIV/ AIDS in Amazonas, Brazil. The Brazilian Journal of In- 
fectious Diseases, 17(6), 701-703.

31. Mahmoud, A., Sherif, N. A., Abdella, R., El-Genedy, A. R., EI Kateb, A. Y., \& Askalani, A. N. (2015) : Prevalence of Trichomonas vaginalis infection among Egyptian women using culture and Latex agglutination: cross-sectional study. BMC women's health, 15 (1), 7.

32. Dahab, M. M., Koko, W. S., Osman, E. E., \& Hilali, A. H. M. (2012) : Prevalence and transmission of Trichomonas vaginalis infection among women in Khartoum State, Sudan. Journal of Public Health and Epidemiology, 4(2), 34-38.

33. Kaul, P., Gupta, I., Sehgal, R., \& Malla, N. (2004) : Trichomonas vaginalis: random amplified polymorphic DNA analysis of isolates from symptomatic and asymptomatic women in India. Parasitology international, 53 (3), 255-262.
34. Hegazi, M. M., Makhlouf, L. M., Elbahey, M. A., ElHamshary, E. M., Dawoud, H. A., \& El-Gayar, E. K. (2009) : Polymerase chain reaction versus conventional methods in the diagnosis of vaginal trichomoniasis. Journal of the Egyptian Society of Parasitology, 39(1), 11.

35. Nassef, N. E., Afif, A. F., Basuni, A. A., El-Nasr, M. F. A., \& Atia, A. F. (2014) : Evaluation of microscopy and polymerase chain reaction for diagnosis of symptomatic and asymptomatic female trichomoniasis. Parasitologists United Journal, 7(1), 37.

36. Muzny, C. A., Blackburn, R. J., Sinsky, R. J., Austin, E. L., \& Schwebke, J. R. (2014) : Added benefit of nucleic acid amplification testing for the diagnosis of Trichomonas vaginalis among men and women attending a sexually transmitted diseases clinic. Clinical infectious diseases, ciu 446.

MANSOURA MEDICAL JOURNAL 
37. Smith, K. S., Tabrizi, S. N., Fethers, K. A., Knox, J. B., Pearce, C., \& Garland, S. M. (2005) : Comparison of conventional testing to polymerase chain reaction in detection of Trichomonas vaginalis in indigenous women living in remote areas. International journal of STD \& AIDS, 16(12), 811815.

38. Shehabi, A. A., Awwad, Z. M., Al-Ramahi, M. E., Charvalos, E., \& Abu-Qatouseh, L. F. (2009) : Detection of Mycoplasma genitalium and Trichomonas vaginalis infections in general Jordanian patients. Am J Infect Dis, 5(1), 7-10.

39. Hegazy, M. M., El-Tantawy, N. L., Soliman, M. M., EISadeek, E. S., \& EINagar, H. S. (2012) : Performance of rapid immunochromatographic assay in the diagnosis of Trichomoniasis vaginalis. Diagnostic microbiology and infectious disease, 74(1), 49-53.

Vol. 43, No. 1 \& 2 Jan. \& April, 2014
40. Valadkhani, Z., Assmar, M., Esfandiari, B., Amirkhani, A., Hassan, N., Lotfi, M. L., \& Ghobadi-rad, S. (2008): Trichomoniasis in asymptomatic patients. Iranian Journal of Public Health, 37(3), 113-117.

41. Wendel, K. A., Erbelding, E. J., Gaydos, C. A., \& Rompalo, A. M. (2002) : Trichomonas vaginalis polymerase chain reaction compared with standard diagnostic and therapeutic protocols for detection and treatment of vaginal trichomoniasis. Clinical infectious diseases, 35(5), 576580.

42. Kassem, H. H., \& Majoud, 0. A. (2006) : Trichomoniasis among women with vaginal discharge in Benghazi city, Libya. Journal of the Egyptian Society of Parasitology, 36(3), 1007-1016.

43. Radonjic, I. V., Dzamic, A. M., Mitrovic, S. M., Arsenijevic, V. S. A., Popadic, D. M., \& Zec, I. F. K. (2006) : 
Wafaa A. Abou-kamar et al ...

257

Diagnosis of Trichomonas

PCR assay. European vaginalis infection: the senJournal of Obstetrics \& Gysitivities and specificities of necology and Reproductive microscopy, culture and Biology, 126(1), 116-120. 